\title{
A Short Review of Cable Yarding Applications in Australia
}

\author{
Mohammad Reza Ghaffariyan \\ Australian Forest Operations Alliance (AFORA), Forest Industries Research Centre, University of the Sunshine \\ Coast, Maroochydore DC, Queensland, Australia
}

\begin{abstract}
The current technology in Australia is mainly large swing tower yarder with grapple. These yarders operate under whole tree or cut-to-length methods in steep terrains of Victoria, Tasmania and South-East Queensland. Cable yarding is often applied in clear fell operations in pine or Eucalypt stands in Australia. Felling operations prior to yarding are carried out manually or using tracked feller-bunchers. Typical terrains for applying cable yarding have slope larger than $30^{\circ}$. There is currently a lack of small to medium size cable yarders that can efficiently operates under different circumstances. Medium size capacity yarders would be required to handle a wide range of situations under uphill and downhill extractions while small capacity highly mobile yarders will be needed for clean-up operations.
\end{abstract}

Keywords: Cable yarding, Yarders, Timber harvesting, Productivity, Steep terrains

\section{Introduction}

Cable-based yarding technology has had a long tradition in Central Europe (Cavalli et al., 2004), the Pacific Northwest Region of the United States and Canada, Japan (Heinimann et al., 2001) and Turkey (Acar and Yoshimura, 1997; Eroglu et al., 2009). During the 1960s, European sledge yarder technology became well known, and in the 1970s, mobile tower yarders began to replace them (Heinimann et al., 2001). Tower yarders are common cable yarding systems in mountainous forests in Europe (Acar and Yoshimura, 1997; Ghaffariyan et al., 2009; Spinelli et al., 2015). Planning for cable yarding systems takes more time than for ground-based systems. Once in place, however, the production rate on steep slopes is comparable to groundbased systems. Most operations using cable yarders are feasible when operating in a high-product-yield stand and when factors affecting production have been carefully evaluated. Cable yarding also has the advantage of minimizing the impact on environmentally sensitive areas, especially when complying with best management practices (BMP) and other forest practice regulations (Huyler and LeDoux, 1997).

The current technology in Australia is mainly large swing tower yarder with grapple. These yarders operate under whole tree or cut-to-length methods in steep terrains of Victoria (Figure 1), Tasmania (Figure 2) and South-East Queensland. According to Parschau (2012) although cable yarding is currently not practiced in the native state forests of New South Wales, cable harvesting has a relatively long history in Australia, spanning from the first steam-driven, skid-mounted systems introduced in the early $19^{\text {th }}$ century to large tower yarders that have been used since the mid-20 $0^{\text {th }}$ century and are still an integral part of managing the country's plantation estate on steeper slopes. However, the conventional application has been mostly associated with clear-cutting operations. In Victoria and Tasmania, the cable yarders are still used for clear-cutting operations in native state forests managed under silvicultural regimes for light-craving tree species such as Australian mountain ash (Eucalyptus regnans). The association of cable yarding with clearcutting native-forests, a highly controversial issue in Australia, may have contributed to a situation where the technology was not envisaged to play a future role in the management of the native forests of New South Wales by the time the current environmental protection License (EPL) was put in place (Forest Corporation NSW, 2010). 


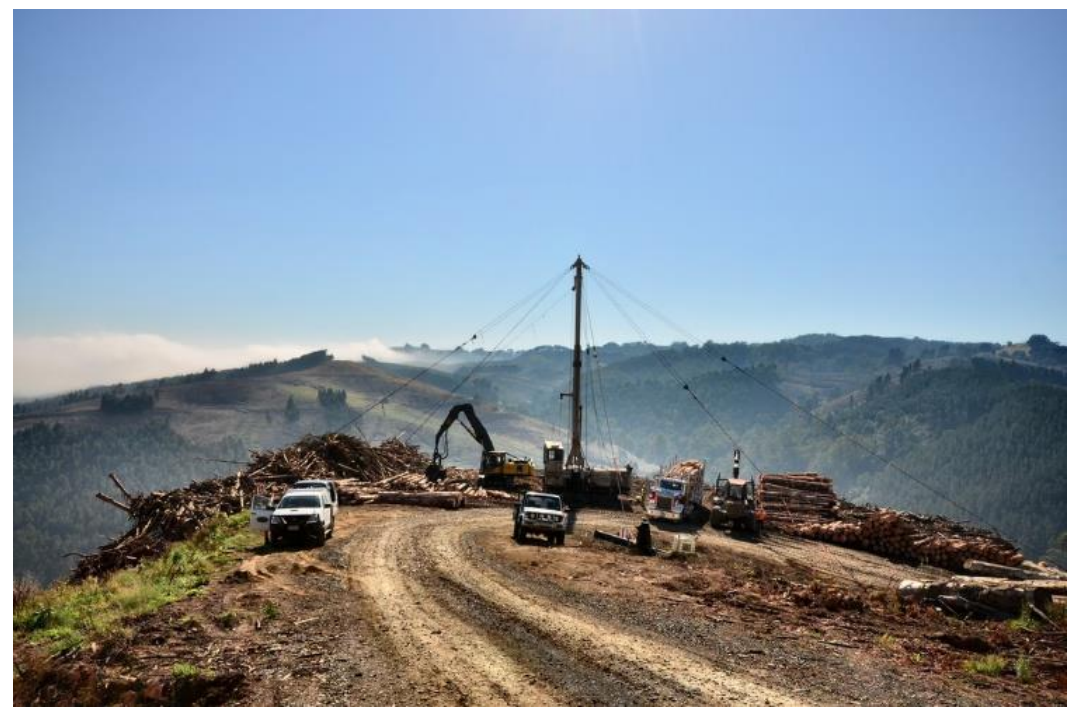

Figure 1. Cable yarding operations in West Gippsland, Victoria (URL 1)

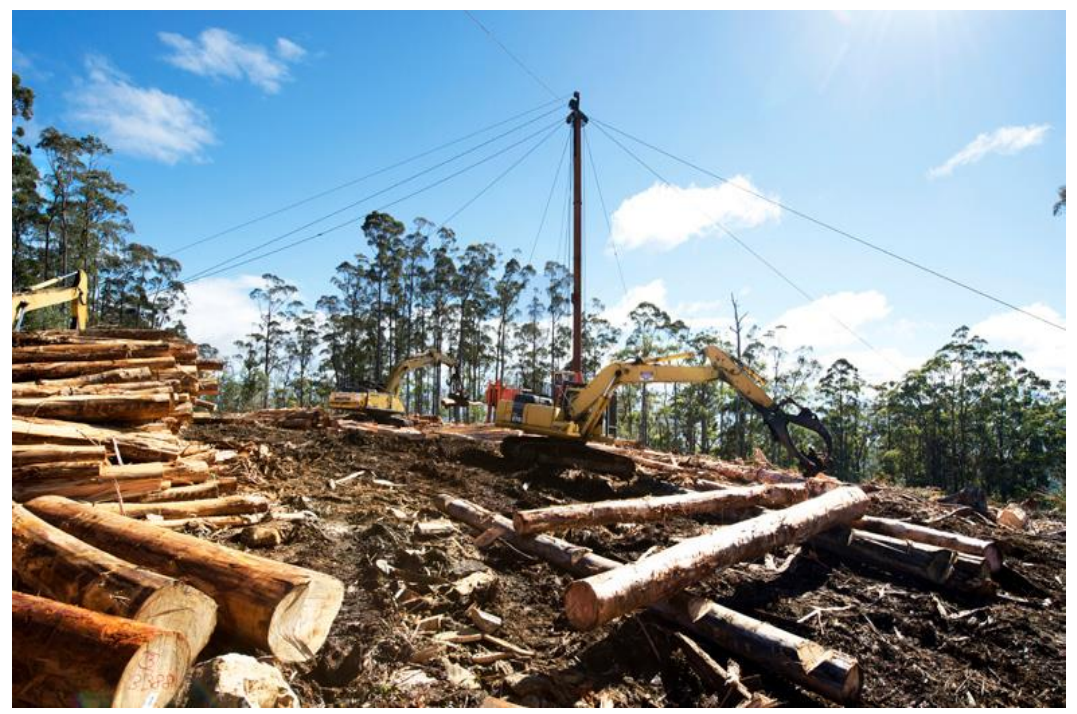

Figure 2. Cable yarding operations in Southern Forest, Tasmania (URL 2)

\section{Legal Requirements, Safety Roles and Operational Procedure}

Each state in Australia has specific code of practice for harvesting operation. In Victoria, one of the regulations is that on slopes greater than $30^{\circ}$ with low or medium soil erosion hazard, and slopes less than $30^{\circ}$ with a high or very high soil erosion hazard, additional measures must be taken to avoid movement of soil into streams, such as the adoption of cable harvesting or the provision of appropriate buffers and filter strips (DEPI, 2014a). In Victoria timber harvesting operations should be planned in a way that clearfall and skyline 'notches' are not apparent from the scenic drives and designated lookouts. Other important factor is soil erosion to be minimized during harvesting operations (DEPI, 2014b).

According to Tasmanian code of practice (Forest Practices Authority, 2015) if cable harvesting is applied to extract timbers to road sides, the road must be protected from excessive shoulder damage and table drains and culverts must be kept clear at all times so as not to concentrate water flows. The other legal requirement in Tasmania is that in karst areas ground based systems will be limited to slopes below $20^{\circ}$. On vulnerable karst soils harvesting on slopes above $9^{\circ}$ will be restricted to uphill cable harvesting. No harvesting will be permitted on slopes above $20^{\circ}$. Forested skylines should be protected by designing coupe boundaries to cross at the toe of skyline slopes or in saddles. Boundaries should preferably cross diagonally to the main viewing direction. An alternative to crossing a skyline is to locate coupe boundaries either behind or in front of the skyline edge.

In Queensland's plantations the regulations' emphasis is that appropriate harvesting methods (e.g. cable harvesting or modified excavator-based methods) should be used where conventional harvest methods are considered unsafe or may threaten the stability of the soil or may have potential for adverse off-site effects (Timber Queensland, 2015). 
In addition to those regulations and safety roles mentioned, Safe Work Australia (2013) and Victorian cable logging guidelines (Hancock Victorian Plantations, 2007) have published a guide on managing the risk of cable operations. Detailed specific safety recommendations have been given on landing size, guyline set up, anchors set up, rigging, blocks/shackles, wire rope, chokers, signaling systems and yarding operations under different circumstances.

\section{Typical Stand and Terrain Characteristics}

Cable yarding is often applied in clear fell operations in pine or Eucalypt stands in Australia. Felling operation prior to yarding are carried out manually or using tracked feller-bunchers. Typical terrains for applying cable yarding have slope larger than $30^{\circ}$. Conventional forwarders and tractors are limited to extract the logs in such steep terrains due to high risk of roll over and extreme soil and stand damages. Thus, forest growers and contactors prefer to use cable logging in mountainous areas.

Based on industry feedback in Victoria, generally the need for cable is determined by the predominance of slopes higher than $28^{\circ}$ (not an absolute measure) in the coupe and the complexity of drainage systems. Building this up into an operational area will see a typical coupe with a slope range of $15^{\circ}$ to $35^{\circ}$, occasionally up to $40^{\circ}$ with a predominance of area being higher than $25^{\circ}$. Maximum extraction distance is about $500 \mathrm{~m}$. Tree dimension predominantly varies in range 0.6 to $1.0 \mathrm{~m}^{3}$ stem size.

A detailed case study has been conducted by Acuna et al. 2011 in 33-years old Radiata pine plantations near Yarram, on the South Gippsland coast of Victoria for a Madil 124 swing yarder for two types of operations including pre-bunched wood operations (by an excavator) and un-bunched wood operation (conventional harvesting). The mean slope in the case study area was $27^{\circ}$. The average yarding distances were $155 \mathrm{~m}$ and 195 $\mathrm{m}$ while the average piece sizes were about $1.9 \mathrm{~m}^{3}$ and $1.3 \mathrm{~m}^{3}$ for pre-bunched wood operations (by an excavator) and un-bunched wood operation (conventional harvesting) respectively. The yarder reached a productivity of $41.6 \mathrm{~m}^{3} / \mathrm{PMH}_{0}$ when extracting bunched wood while average productivity for unbunched wood was about $33.9 \mathrm{~m}^{3} / \mathrm{PMH}_{0}$. The study results indicated that pre-bunching could increase the productivity up to $24 \%$.

Another study was carried out to determine impacts on site disturbance and selected soil properties resulting from cable-logging wet eucalypt forest developed on granite substrates in northeastern Tasmania (Laffan et al., 2001). The results show that both the area and depth of soil surface disturbance are relatively minor, with ca. $11 \%$ of the study coupe affected by moderate (litter and part topsoil removed) or severe (subsoil exposed) disturbance. Cable draglines accounted for just over 7\% of the soil disturbance ( $7 \%$ moderate and $0.2 \%$ severe), whereas tree uprooting associated with the logging accounted for a further 3\% moderate disturbance and $1 \%$ severe disturbance. Measurements of soil properties in the surface layer $(0 \pm 10 \mathrm{~cm})$ show that bulk density is ca. $20 \%$ higher and organic carbon content $(\mathrm{kg} / \mathrm{ha})$ is $15 \%$ lower on cable draglines compared to undisturbed sites. However, the dominant type of soil disturbance caused by cable-logging appears to have been displacement of the upper $10 \mathrm{~cm}$ of topsoil from the center to the outside edges of draglines rather than compaction in situ.

Comparison of the data with studies of ground-based logging of wet native forests elsewhere in southeastern Australia shows that cable-logging has resulted in significantly less impact on both area of soil disturbed and soil properties. The results are also discussed in relation to relevant sustainability indicators (soil erosion, organic matter and compaction) specified in Criterion 4 of the Montreal Process together with recently proposed threshold values (Laffan et al., 2001).

\section{Current Limitations of Applied Technologies}

There is a lack of small to medium size cable yarders that can efficiently operate under different circumstances. Also, in some parts of mountainous area ground based machines have been applied and pushed to their technical limits due to lack of modern cable yarding systems which might cause serious soil compactions and erosions issues over long-term period. One of the main issues of available yarders is the large machine size which causes higher extraction costs. Thus, larger operating area and higher cutting volume per hectare are required to be economically viable. The large machines can't be effectively matched with thinning operations with lower harvest intensity (e.g. pine plantations on steep terrains in Victoria) because of the size and cost. There have been some limitations when applying cable systems in Australia. Two forest companies in New South Wales and Victoria applied cable yarding in the past but they do not tend to apply them further due to following problems;

- Shovel logging might be more cost-effective method for harvesting most areas of their steep terrains while suitable areas for cable yarding is very small. Application of cable systems in such small area has highly increased the extraction costs.

- The applied cable yarding systems had limited success due to terrain characteristics, i.e. convex shape and relatively small settings (harvesting areas smaller than 10 hectares).

The other challenging aspect is that some of their forest estate is based as Eucalypt plantations that are harvested on a 10-year rotation resulting in small piece sizes of $0.2 \mathrm{~m}^{3}$.

Hand felling is not preferred so generally fellerbunchers are used for shoveling on steep slopes. 


\section{Conclusions and Future Technical Developments/ Requirements}

Parschau's study (2012) confirmed this fact that a selective harvesting operation which applied a cable harvesting system based on a small mobile tower yarder (e.g. Valentini V850-M-2 Bush and the EMS Woodsman) in addition to the ground-based system could access between two and five times more of the potential net harvest area than using the ground-based harvesting system. To be economically viable, however, the cable system would have to concentrate on harvesting high-quality products only. Under that condition, Parschau (2012) indicated that combined ground-based and cable yarding operation would generate a net revenue between twice and five times of that gained from a ground-based operation alone. Forest companies that are currently applying cable yarding systems (e.g. in Victoria and Tasmania) have indicated three potential areas for future technological developments;

- Large capacity yarder that can handle a wide range of situations under uphill and downhill extractions.

- Small capacity highly mobile clean-up operation.

- Restricted to clear fell operations (high lead is most common practice but some skylines (mainly small size machines and/or lighter rope/carriages) might be required).

For either option safety needs to be paramount (e.g. no one exposed on the slope, minimize need for manual felling). There is the market potential for smaller and more mobile yarders to clean up small difficult pockets, potentially working across the state given the lack of scale for this work at a regional level.

\section{Acknowledgment}

The author would like to thank participation of following industry partners in this project; HQP, Forestry Tas, HVP, FCNSW and Midway Ltd. Dr Mauricio Acuna provided useful information used in this review.

\section{References}

Acar, H., Yoshimura, T. 1997. A Study on the productivity and cost of cable logging in Turkey. Journal of Forest Research, 2(4):199-202.

Acuna, M., Skinnell, J., Mitchell, R., Evanson, T. 2011. Bunching with a self-levelling feller-buncher on steep terrain for efficient yarder extraction. Croatian Journal of Forest Engineering, 32 (2):521-531.

Cavalli, R., Ientile, F., Menegus, G. 2004. Cable crane use under sustainable forest management in NorthEastern Italian Alps. In: Proc. of the Cable Yarding Suitable for Sustainable Forest Management Symposium, Sept. 23-25, Idrija, Slovenia. pp. 51-66.
DEPI, 2014a. Department of Environment and Primary Industries (Victoria), Code of Practice for Timber Production 2014. 80 p. http://www.depi.vic.gov.au (Accessed: 3 July 2017)

DEPI, 2014b. Department of Environment and Primary Industries (Victoria), Management Standards and Procedures for timber harvesting operations in Victoria's State forests. 198 p. http://www.depi.vic.gov.au (Accessed: 3 July 2017)

Eroglu, H., Özkaya, M.S., Acar, H.H., Karaman, A., Yolasigmaz, H.A. 2009. An investigation on roundwood extraction of Fagus orientalis lipsky, Abies nordmanniana (Stew.) Spach. and Picea orientalis (L.) Link. by Urus M III forest skyline on snow. African Journal of Biotechnology, 8(6):10821089.

Forest Corporation NSW, 2010. Review of world cable harvesting practices. Unpublished report.

Forest Practices Authority, 2015. Forest Practices Code 2015. 133 p., Tasmania. http://www.fpa.tas.gov.au (Accessed: 3 July 2017).

Heinimann, H.R., Stampfer, K., Loschek, J., Caminada, L. 2001. Perspectives on Central European cable yarding systems. In: Proc. of the International Mountain Logging and 11th Pacific Northwest. Skyline Symposium, Dec. 10-12, Seattle, WA. pp. 268-279.

Hancock Victorian Plantations. 2007. Victorian cable logging guidelines. $155 \mathrm{p}$.

Huyler, N.K., LeDoux, C.B. 1997. Cycle-time equation for the KollerK300 cable yarder operating on steep slopes in the Northeast. Research Paper NE-705. USDA Forest Service.

Ghaffariyan, M.R., Stampfer, K., Sessions, J. 2009. Production equation of tower yarders in Austria. International Journal of Forest Engineering, 20(1):17-21.

Laffan, M., Jordan, G., Duhig, N. 2001. Impacts on soils from cable-logging steep slopes in northeastern Tasmania, Australia. Forest Ecology and Management, 144:91-99.

Parschau, J. 2012. Planning and Assessment for Cable Harvesting Systems for Selective Harvesting in Native Forests of New South Wales. Special Scholarship Project (SRP301), University of the Sunshine Coast. 32 p.

Safe Work Australia. 2013. Guide to managing risks in cable logging. Published in December 2013. 59 p. http://www.safeworkaustralia.gov.au (Accessed: 3 July 2017).

Spinelli, R., Maganotti1, N., Visser, R. 2015. Productivity models for cable yarding in Alpine 
forests. European Journal of Forest Engineering, 1(1):9-14.

Timber Queensland. 2015. Timber plantation operations code of practice for Queensland. $56 \mathrm{p}$. http://www.timberqueensland.com.au (Accessed: 3 July 2017).
URL 1, http:// www.flickr.comphotosphunnyfotos 16658936391 (Accessed: 10 Oct. 2018)

URL 2, Sustainable Timber Tasmania. Fact sheet no.6. Cable Harvesting. http://www.sttas.com.au (Accessed: 17 October 2018). 